\title{
MODERNISATION OF A LIFT THAT CONSTITUTES PART OF THE BREATHING SIMULATOR, EQUIPMENT PaRT 2
}

Zbigniew Talaśka, Bartłomiej Jakus

Naval Academy, Department of Underwater Works Technology in Gdynia, Poland

\section{ABstRACT}

This article is a continuation of the article published in issue No. 3 (64) 2018 of Polish Hyperbaric Research, which demonstrated the scope of changes which a typical car lift should be subjected to in order to extend its functionality to that of a hoist, that lifts the lid of the decompression chamber, in a breathing simulator used at the Department of Underwater Works Technology of the Naval Academy in Gdynia.

Keywords: breathing simulators, equipment of breathing simulators.

\section{ARTICLE INFO}

PolHypRes 2019 Vol. 68 Issue 3 pp. 7 - 32

ISSN: 1734-7009 elSSN: 2084-0535

DOI: $10.2478 / \mathrm{phr}-2019-0010$

Pages: 26, figures: 23, tables: 1

page www of the periodical: www.phr.net.pl

Publisher

Polish Hyperbaric Medicine and Technology Society

\section{Original article}

Submission date: 17.06.2019 r.

Acceptance for print: 13.08.2019 r. 


\section{INTRODUCTION}

The moernisation of a car lift and adapting it to the function of the hoist that lifts the movable cover of a decompression chamber would require certain structural changes, the list of which is presented in part I of this article.

In the presented article, the authors attempted to analyse and describe the qualitative changes that need to be introduced in order to make it possible to use the lift for the required purpose, and to carry out their risk analysis and the analysis of their impact on the technical and operational value of the device. It was decided that the analysis and verification calculations should cover, first of all, the issues related to the strength of the lift structure and the required changes in the way its operation is controlled, which result from the proposed manner of positioning the hoist in the room. The obtained results should constitute a basis and argumentation for assessing whether the implementation of the proposed adaptations will lead to the introduction of changes significant enough to give rise to the creation of a new machine.

Later in the article the authors will use the term 'modernisation', which is in accordance with the rules of making changes in the construction of devices applied by the Polish Office of Technical Inspection (UDT) [3]. Therefore, all technical and operational parameters in descriptions and drawings will be marked with indicators in the following manner: ' $\mathrm{s}$ ' - for a standard solution (lifting - lowering of vehicles), ' $m$ ' - for a solution after the modernisation (lifting-lowering of the lid of a decompression chamber).

\section{THE SCOPE OF LIFT HEIGHT AND REQUIREMENTS RELATED TO THE POSITIONING OF LIFTING EQUIPMENT (LIFT)}

The analysis of the possibility of adapting the lift to the purpose in question started with diagnosing and determining the basic dimensions necessary for the proper functioning of the device. The information contained in “Operating Instructions v. 09.09", attached to the lift by the Manufacturer, hereinafter referred to as 'Instructions [1], is used as the reference point.

Figure 1 demonstrates a comparison of the lift applications for standard conditions and after the proposed modernisation with basic dimensions.

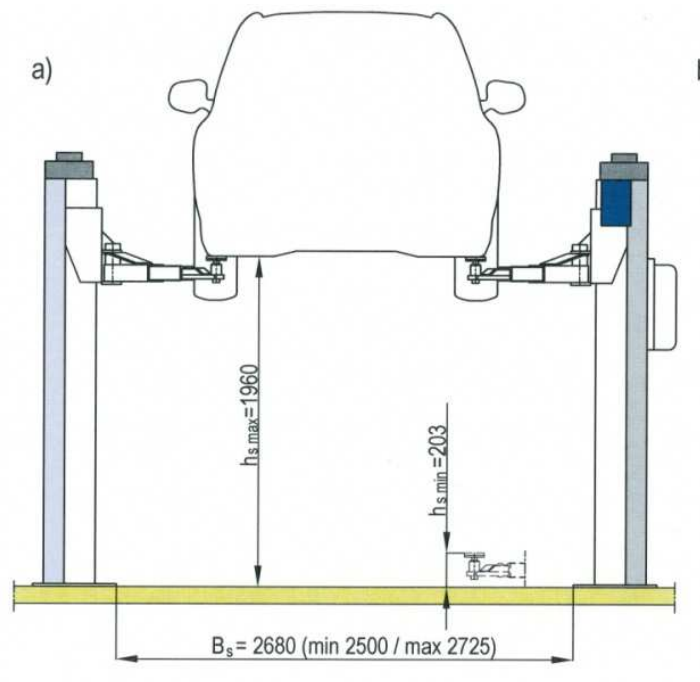

b)

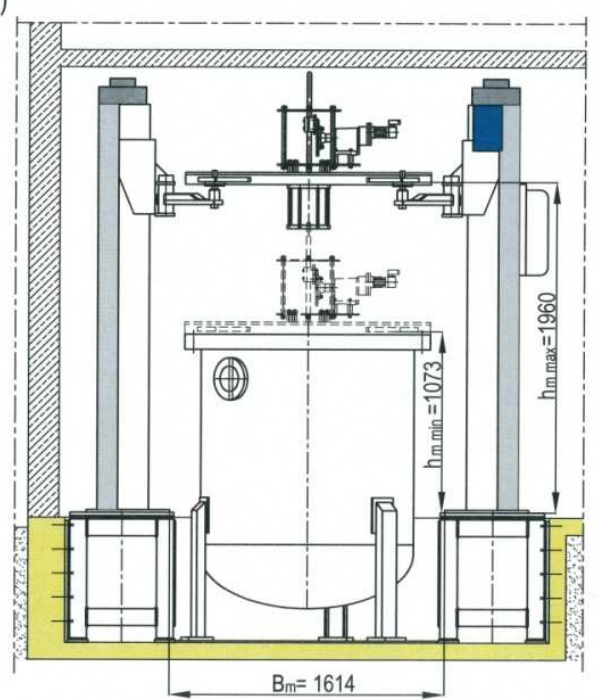

Fig. 1 Comparison of the applications of lift type 254 S4 with its basic dimensions (study drawing):for standard conditions, b) after the proposed modernisation.

For standard solutions, the following dimensions were assumed: the average column spacing $\mathrm{B}_{\mathrm{S}}=2680 \mathrm{~mm}$ from the possible range of $2,500 \div 2,725 \mathrm{~mm}$ and height $\mathrm{h}_{\text {smin }}=203 \mathrm{~mm}$ and $\mathrm{h}_{\text {smax }}=1,960 \mathrm{~mm}$ with the use of additional $60 \mathrm{~mm}$ high sleeves (part L956, Instruction, page 7, Fig. 7). Dimension B is the column spacing of the lift measured between the inner edges of their bases in [mm].

For a solution where the lid is lifted, with the positioning of lift columns at the level of the decompression chamber foundation in the cavity, the required vertical range for the operation of trolleys would be from $h_{\min }=1,843 \mathrm{~mm}$ to $h_{\max }=2,730 \mathrm{~mm}$. The room height would then be fully utilised and the comfort of operation of the devices suspended under the lid in the raised position would be ensured. The maximum lifting dimension required in this case would, however, exceed the technical capabilities of the lift.

Therefore, truss construction supports with a height of approx. $770 \mathrm{~mm}$ should be used under the columns. They should be placed on the floor of the trench on both sides of the tank of the decompression chamber with a lifted lid, as shown in Fig. 1 b. They should be designed for mounting in the ground and side walls, e.g. with screws and wall plugs. In the upper part, plates with a thickness of not less than $20 \mathrm{~mm}$ welded on the perimeter of the load-bearing structure would be required. These would form the 'foundation' for attaching the column bases with M16 bolts and nuts according to the installation instructions. 
Fig. 2 shows the design of the required lift column support structure.
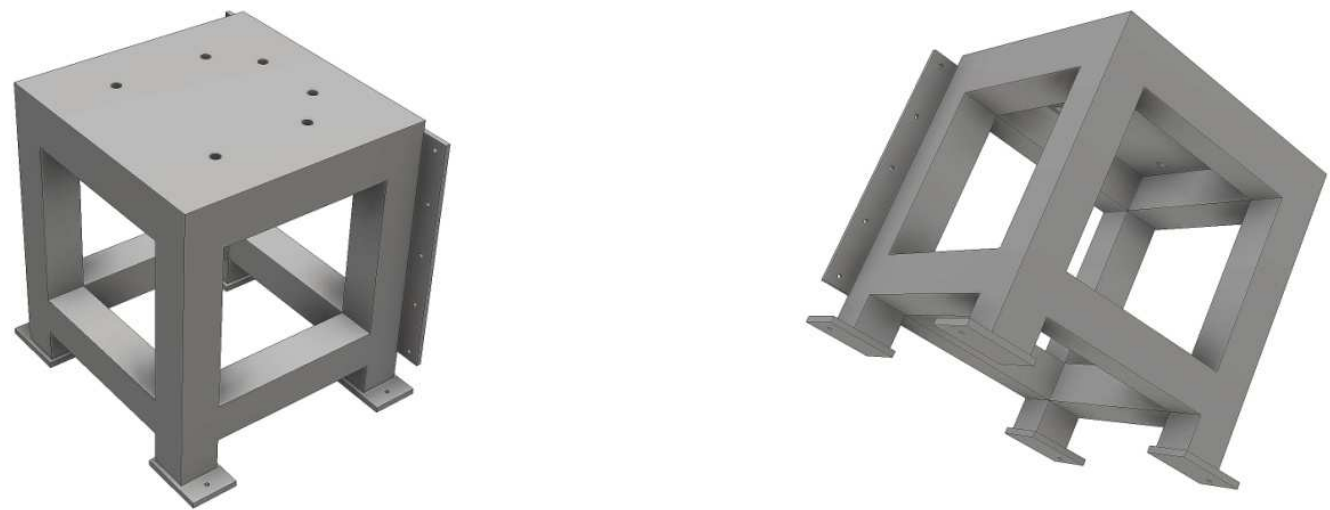

Fig. 2 shows the design of the required lift column support structure (study drawing by M. Palczewski-Haska).

After taking account of the diameter of the tank of the decompression chamber, the dimensions of the trench in the floor of the room, the construction of supports and the required positioning of the supports in the trench, the spacing between the columns turned out to be the resulting dimension with the value of $B_{m}=1614 \mathrm{~mm}$.
Table 1 presents a summary comparison of the basic operating dimensions in the analysed design solutions.

Comparison of the basic operating dimensions of the lift in the analysed construction solutions.

\begin{tabular}{|c|c|c|}
\hline $\begin{array}{l}\text { The standard constructior } \\
\text { with an additional } \\
\text { 60mm high sleeve } \\
\text { (Part L956) }\end{array}$ & $\begin{array}{l}\text { Requirements for a lifted } \\
\text { object before } \\
\text { modernisation }\end{array}$ & $\begin{array}{ll}\text { Construction } & \text { after } \\
\text { modernisation with } \\
\text { supports under the } \\
\text { columns with the } \\
\text { height of } 770 \mathrm{~mm}\end{array}$ \\
\hline 203 & 1,843 & 1,073 \\
\hline 1,960 & 2,730 & 1,960 \\
\hline $2,500 / 2,725$ & $\geq 1,500$ & 1,614 \\
\hline
\end{tabular}

In the event of the modernisation of the lift, its lifting units with additional lifting sleeves of $60 \mathrm{~mm}$ in height (part L956) will move along the columns in the height range of lifting and lowering typical for the lift as specified by the Manufacturer.

\section{THE ARMS OF THE LIFTING UNIT TROLLEY} ON THE LIFT COLUMNS

The arms constitute the most significant construction element of the lift. For this reason, they were subjected to a detailed analysis, assuming that they have the greatest impact on the manner of using the device and its safety.

The lift in question is typically equipped with four extendible arms, symmetrically mounted to the trolleys lifted on both columns. Extending them and placing the supporting lugs at the four points of the vehicle support enables the vehicle to be lifted to a certain height within the permissible lifting range.

Figure 3 shows the design of the extendible arm and a standard lifting unit installed on the elevator column. 
a)

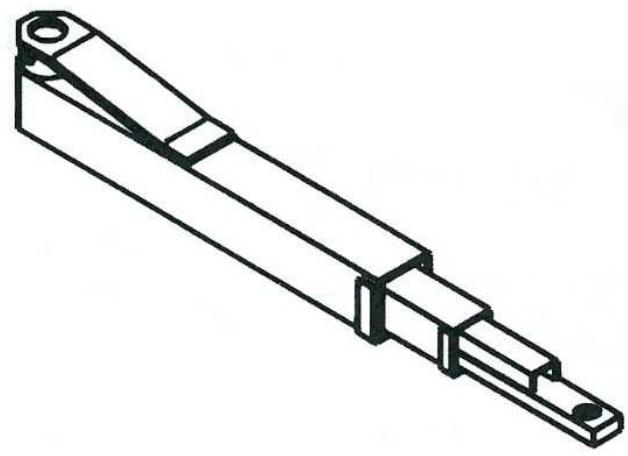

b)

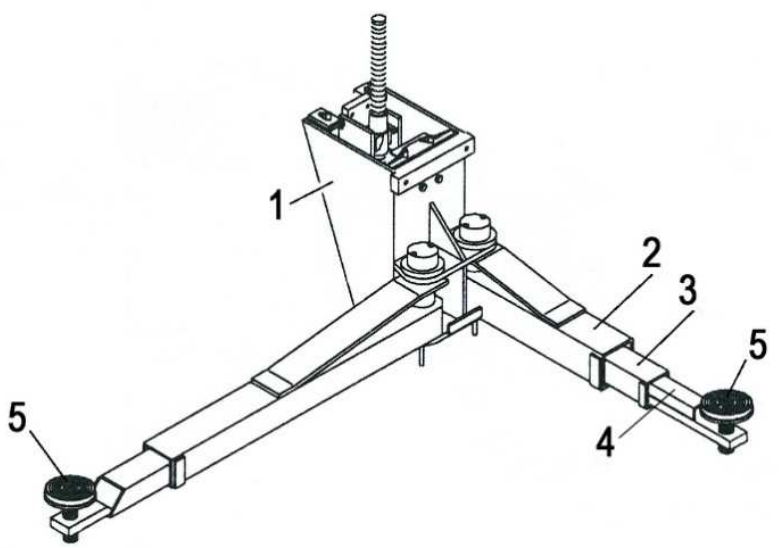

Fig. 3 Standard components mounted on the lift type $254 \mathrm{~S} / 4$ [2], a) construction of the extendible lifting arm; b) construction of the lifting trolley together with lifting arms and lugs: 1 - lifting trolley, 2, 3, 4 - extendible arms, 5 - lugs.

Standard extendible arms (Fig. 3a) are made of 3 parts which telescope, which allows them to be adjusted in length. According to the manufacturer's documentation, fully telescoped arms have a minimum operating length of approx. $1_{\operatorname{smin}}=730 \mathrm{~mm}$. This means that with the required positioning of the columns in the trench, it would be impossible to use them, in their existing form, to lift the lid at its four support points. This is due to the fact that the location where the decompression chamber is positioned requires the columns to be placed in such a way that the operating length of the arms between the support points and the rotation axis should be approx. $\mathrm{l}_{\mathrm{m}}=549 \mathrm{~mm}$.

Fig. 4 shows the appearance of a standard, extendible arm mounted to the lifting unit with a lug and a $60 \mathrm{~mm}$ high sleeve.

Fig. 4 Standard arm mounted to the lifting unit of the lift (own photo).

Fig. 5 shows the required arrangement of the lift arms and their dimensions to ensure lifting and lowering the decompression chamber lid within the specified height range.

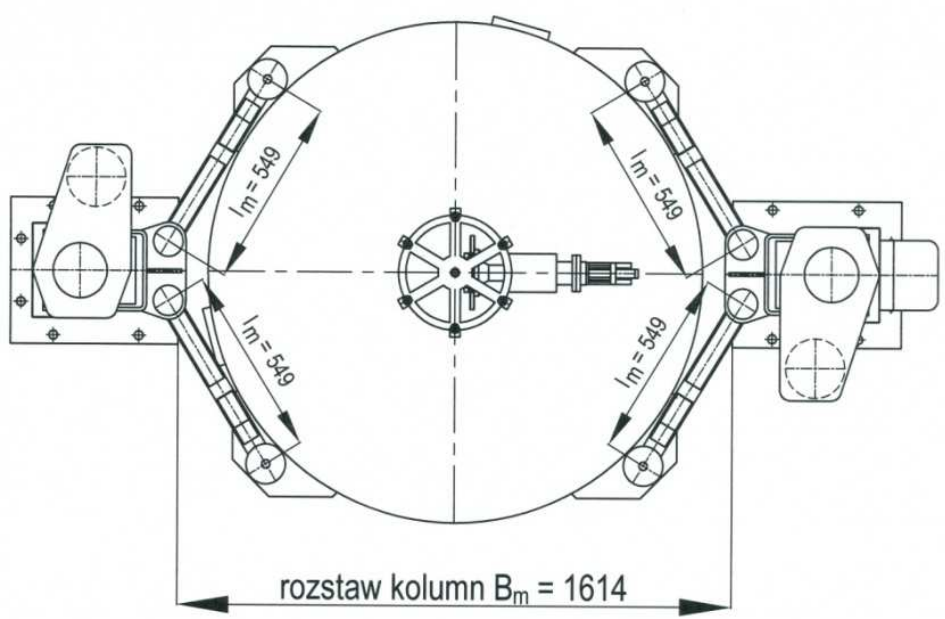

Fig. 5 The required arrangement of the lift arms and their dimensions to ensure lifting and lowering of the decompression chamber lid at the location of positioning the chamber and the columns (study drawing). 
It has been assumed that the last extendible part of the standard lift arm could be used to achieve the objective. It has a hole at its end enabling the placement of a lug in it, which is used to support the lifted elements. The modernisation of this part of the arm would consist in the appropriate shortening of the arm and connecting it to the spacer sleeve of the new construction, which would constitute the mounting and the rotation axis in the lift unit trolley.

Figure 6 shows the required arm structure for lifting the decompression chamber lid.

Fig. 6 The required arm structure for lifting the decompression chamber lid (study drawing by M. Palczewski-Haska).

\section{LUGS OF ARMS}

The lugs are an indispensable part of the equipment of each of the four arms of the lift. In standard use, they are mounted in holes at the ends of the last, extendible parts of the lifting arms. They are used as support points with the possibility of removing the clearances by adjusting their height, in order to

a)

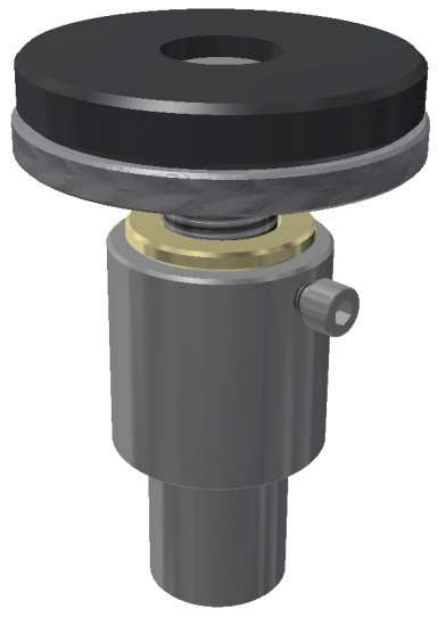

simultaneously and evenly lift the vehicle. They are constructed as a unit consisting of bolts screwed into nuts and sleeves with one side bevelled, which in turn are inserted in one fixed position into the arm holes and locked in place by small counter-rotating screws.

Fig. 7 shows a standard lug mounted at the end of the lift arm together with a $60 \mathrm{~mm}$ high sleeve.

Fig. 7 A standard lug mounted at the end of the lift arm together with a sleeve: a lug set with a sleeve (study drawing by M. Palczewski-Haska), b) how the lug is mounted on the arm [2].

The raised vehicle is practically unprotected against slipping off the lugs and falling in the lift area. Therefore, during the modernisation process it was assumed that the lugs should be restructured in such a way that:

- they enable independent removal of clearances at the junction with the lugs of the decompression chamber lid,

- they protect and prevent accidental sliding of the raised lid,
- they ensure precise positioning of the lid in the upper mounted ring of the decompression chamber.

Fig. 8 shows the required design of the lug with a sleeve for raising/lowering the top lid of the decompression chamber. 
a)

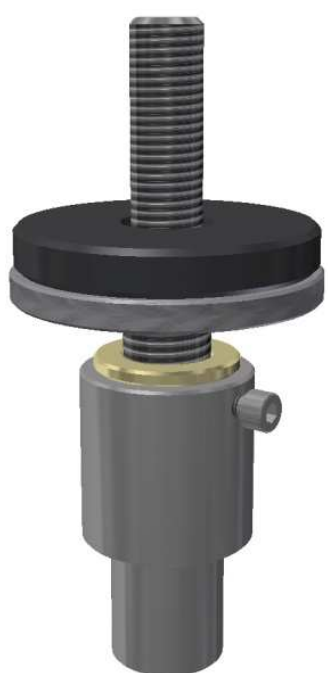

b)

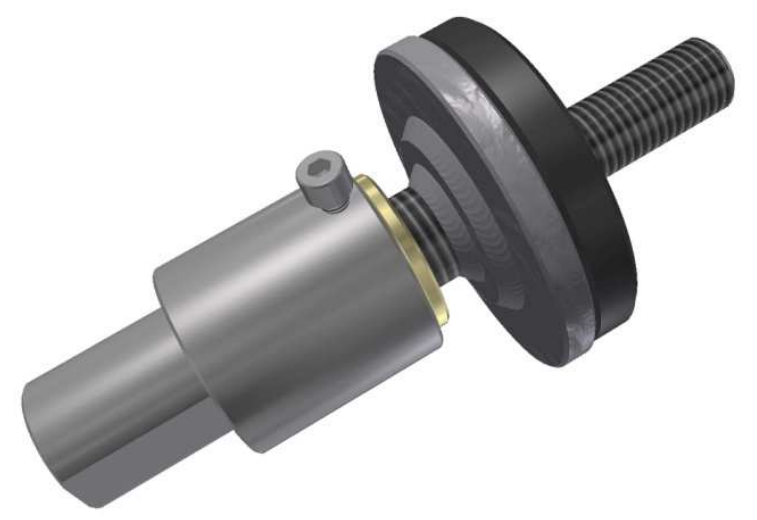

Fig. 8 The required design of the lug for raising/lowering the top lid of the decompression chamber together with the sleeve (study drawing by M. PalczewskiHaska).

It should be noted that the modernised lugs, when installed in the holes of the lift arms in connection with the holes in the load-bearing lugs on the perimeter of the decompression chamber lid, constitute an important protection against possible slipping and falling of the plate to one side. Since only one object with fixed support points will be lifted, this means that the lid's arms will be constantly kept apart, and the lid itself will be lifted in a fixed position.

From the point of view of the forces that encumber the individual lift lugs, the lid is a kind of structural 'beam' that prevents the columns from tipping towards the centre, i.e. on the decompression chamber. The required structural change of the lugs will ensure increased safety during the operation of the modernised equipment.

\section{COMPARISON OF THE STANDARD LIFT}

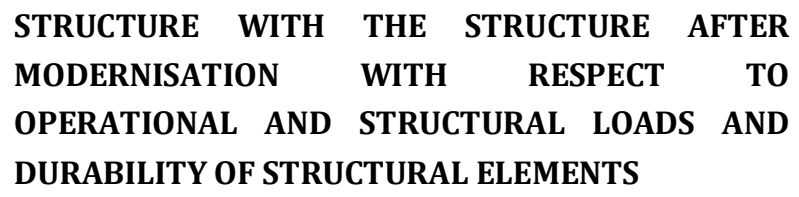

The following loads and stresses were analysed in order to compare the two structures:

- the lifted weight,

- pressure on the ground for each of the lift's columns,

- the bending moment of the column in the transverse plane $(\mathrm{x}, \mathrm{y})$,

- the bending moment of the column in the longitudinal plane $(\mathrm{x}, \mathrm{z})$,

- the bending moment of the arms of the lifting unit.

The analysis assumes that the total load of the lifting object is distributed evenly over both columns of the lift.

In analysing the bending of the column and arms the following coordinate system has been assumed, similar as for the bending beam:

- clockwise system of $x, y, z$ coordinate axis,
- beginning of the system in the centre of gravity of the transverse section of the column (arm) in the spot where the column (arm) is fixed,

- $\quad x$ axis along the column height (arm length),

- coincidence of the $y$ and $z$ axes with the main inertia axes of the transverse section of the column (arm).

\section{BASIC LOADING OF THE LIFT AND THE GROUND BENEATH THE LIFT}

The standard construction assumes the maximum lifted weight $\mathrm{m}_{\mathrm{Smax}}$ equal to the load capacity of the device with the value of $\mathrm{m}_{\text {Smax }}=4,000 \mathrm{~kg}$ (according to the instructions, pg.7, section II). This results in the overall load of the lift with the P $\mathrm{Smax}_{\mathrm{m}}=39,24 \mathrm{kN}$ force and vertical forces from this force in columns with the value of $\mathrm{P}_{\mathrm{Sk}}=$ $19,62 \mathrm{kN}$ - Fig. 9. 


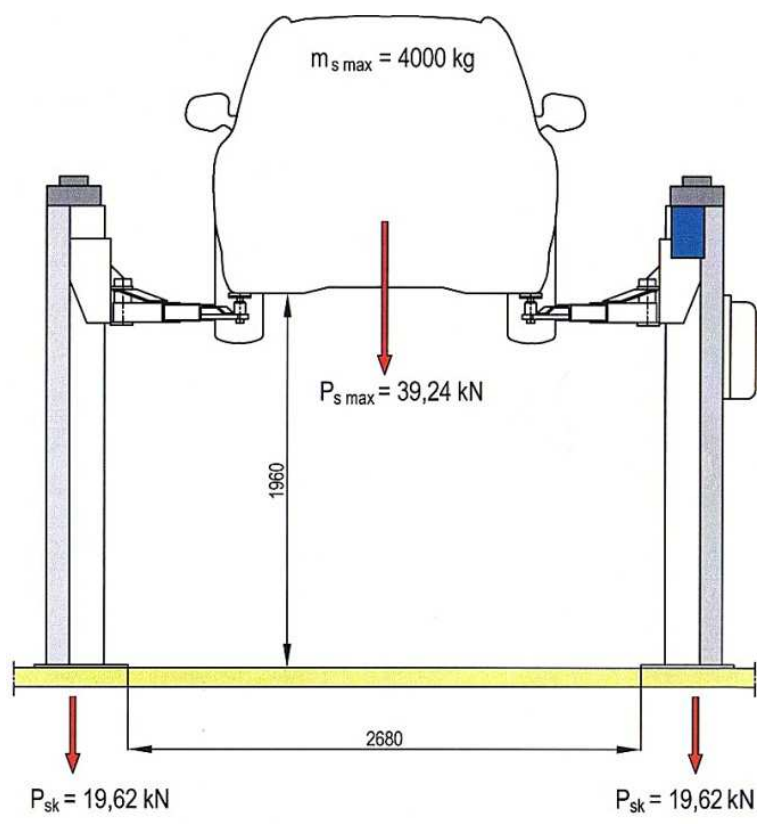

Fig. 9 Vertical forces from the lifted object actingon the lift with standard structure.

In order to determine the pressure on the ground, the weight of one column $\mathrm{m}_{\mathrm{Swk}}$ was assumed as half of the dry weight of the device equal to $\mathrm{m}_{\mathrm{swk}}=345 \mathrm{~kg}$. Hence, the additional vertical force from the column weight was $\mathrm{P}_{\text {Swk }}$ $=3.38 \mathrm{kN}$.

The pressure on the ground under the psk column was determined for the overall vertical force acting on the ground and surface of the rack of the column with dimensions $490 \mathrm{~mm} \times 420 \mathrm{~mm}$ equal to $\mathrm{S}_{\mathrm{sk}}=205,800 \mathrm{~mm}^{2}$.

$$
p_{s k}=\frac{P_{s k}+P_{s w k}}{S_{s k}}=\frac{19620 \mathrm{~N}+3380 \mathrm{~N}}{205800 \mathrm{~mm}^{2}}=0,112 \mathrm{~N} / \mathrm{mm}^{2}
$$

For the structure after the modernisation, the maximum lifted weight $\mathrm{m}_{\operatorname{mmax}}$ was assumed to be equal to the weight of the lid together with the mounted test equipment equal to $m_{\max }=1,360 \mathrm{~kg}$. This results in the overall load of the lift with the $P_{\max }=13,34 \mathrm{kN}$ force and vertical forces from this force in columns with the value of $\mathrm{P}_{\mathrm{mk}}=6,67 \mathrm{kN}$ - Fig. 10 .

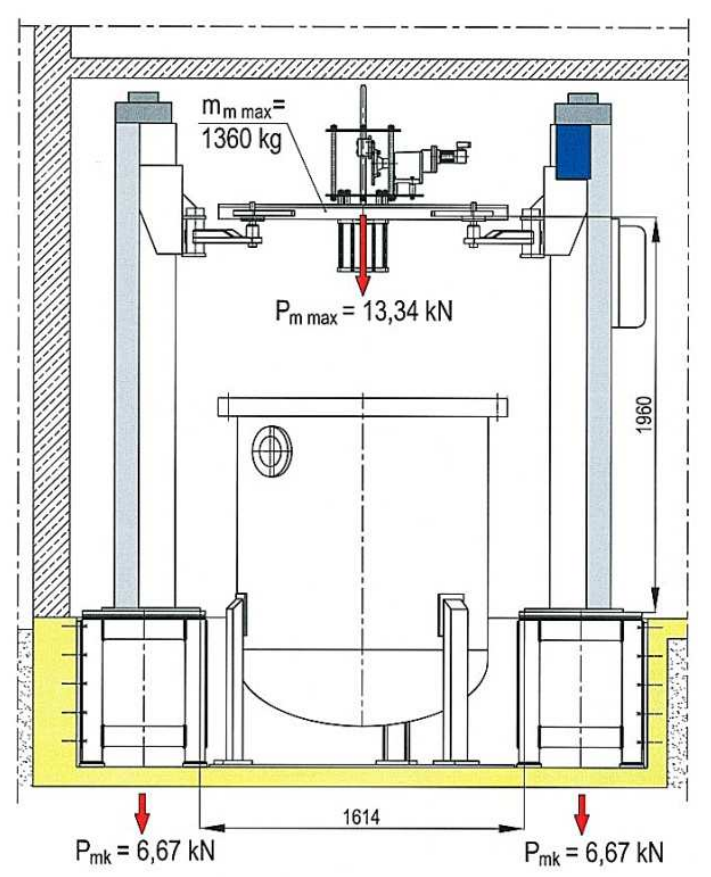

Fig. 10 Vertical forces from the lifted object acting on the lift of the construction after its modernisation. 
The following loads were additionally assumed to determine the pressure on the ground under one column:

- dry weight of one column after modernisation $m_{\text {mwk }}$ was assumed as half of the dry weight of the lift with modernised arms and lugs equal to $\mathrm{m}_{\mathrm{mwk}}$ $=306 \mathrm{~kg}$. Additional vertical force from the weight of the column amounts to $P_{\mathrm{mwk}}=3.00 \mathrm{kN}$.

- dry weight of the column base $\mathrm{m}_{\mathrm{pk}}$ according to construction documentation equal to $\mathrm{m}_{\mathrm{pk}}=242$ $\mathrm{kg}$.

The additional vertical force from the base weight is $\mathrm{Ppk}=$ $2.37 \mathrm{kN}$.

There is a frame installed at the control column base, where the measuring cabinet and the control panels for the breathing simulator and the lift's electrical installation are mounted. The overall weight of this equipment is $m_{\mathrm{el}}=108 \mathrm{~kg}$.

The additional vertical force from the base weight is $\mathrm{P}_{\mathrm{el}}=1.06 \mathrm{kN}$.

The pressure on the ground under the control column $\mathrm{p}_{\mathrm{mk}}$ is determined for the overall vertical force acting on the ground and the area of 4 lugs under the feet of the column support with the dimensions $182 \mathrm{~mm} \times 124$ $\mathrm{mm}$. The total area of the lugs of the support is $\mathrm{S}_{\mathrm{ak}}=90272$ $\mathrm{mm}^{2}$.

\section{LIFT COLUMN BENDING MOMENTS}

Lifting objects using the lift arms causes the column to bend in a complex manner. For the analysis of bending the lift column, bending moments that result from the loading of the column by forces acting on the column from the lifted object in two planes perpendicular to each other have been determined.

The following designations and interpretations have been adopted:

$\mathrm{MZ}$ - bending moment depending on the vertical force acting on the column from the lifted object at the point of lug support on the arm of the lifting unit, and the distance depending on the position of the support points on the width of the object being lifted with respect to the $x$-axis of the lift column. Hereinafter referred to as the 'trans-verse' moment.

MY - bending moment depending on the vertical force acting on the column from the lifted object at the point of lug support on the lifting unit arm, and the distance depending on the position of the support point along the length of the lifted object relative to the $x$-axis of the lift column. There are bending moments with opposite directions of operation, and with different arm lengths of the lifting device also with different values. Hereinafter referred to as the 'longitudinal' moment.

For the standard structure, the following data has been adopted for vehicle lifting (in accordance with the Instruc-tions, pg. 8, section II, fig. 8 and fig. 9):

- $\quad$ maximum lifted weight $\mathrm{mSmax}=4,000 \mathrm{~kg}$, equal to the load capacity of the device,

- maximum width of the vehicle $2,200 \mathrm{~mm}$;

- maximum wheelbase of the vehicle $3,000 \mathrm{~mm}$;

- distribution of the load capacity on the axles of the vehicle interchangeably in two values and for two different arm lengths of the lifting device (maximum/resulting): variation 1:

- $\quad$ an arm with a maximum length and load capacity of $2,660 \mathrm{~kg}$,

- $\quad$ an arm with a resulting length and load capacity of $1,340 \mathrm{~kg}$;

variation 2:

- $\quad$ an arm with a resulting length and load capacity of $2,660 \mathrm{~kg}$,

- $\quad$ an arm with a maximum length and load capacity of $1,340 \mathrm{~kg}$.

On the basis of the above data, a model was adopted to determine the bending moments of the column in both bending planes - Fig. 11, in which:

- the maximum distance between the columns is 2,725 mm (Instruction, pg. 7, Fig. 7),

- maximum distance between the support points in the vehicle width is $2,000 \mathrm{~mm}$,

- maximum distance between the support points in the vehicle length is $2,400 \mathrm{~mm}$,

- one pair of arms of the lifting units remains at the maximum extension $\left(\mathrm{l}_{\mathrm{s} 1}=1,500 \mathrm{~mm}\right.$ ) and the other at the resulting extension to the support point,

- loads on the arms' lugs at the support points with the forces concentrated for the assumed load distribution for one column are:

$\checkmark \quad$ for the arm with the maximum length: $\mathrm{P}_{\mathrm{Spl}}=\mathrm{P}_{\mathrm{Spp}}$ $=13,05 \mathrm{kN}$ (variation 1) or 6,58 $\mathrm{kN}$ (variation 2),

$\checkmark \quad$ for an arm with the resulting length: $\mathrm{P}_{\mathrm{Stl}}=\mathrm{P}_{\mathrm{Stp}}=$ $6,58 \mathrm{kN}$ (variation 1) or 13,05 kN (variation 2).

Based on the diagram (Fig. 11), the distances, along the ' $y$ ' and ' $z$ ' axes, of the points of applying concentrated forces from the rotation axis of the lifting unit arms were determined, assuming the axis of rotation as the place of attaching the rigid arm to the column. The distances are respectively:

- for the arm of maximum length: $\mathrm{ys}_{\mathrm{s}}=588 \mathrm{~mm}$, zs1 $=1,533 \mathrm{~mm}$,

- $\quad$ for the arm of resulting length: $\mathrm{ys} 2=588 \mathrm{~mm}, \mathrm{zs} 2$ $=-875 \mathrm{~mm}$.

The calculation of the transverse bending moment of the 'second' column:

$$
\begin{gathered}
M_{s z}=M_{s z 1}+M_{s z 2}=P_{s p l} \cdot y_{s 1}+P_{s t l} \cdot y_{s 2} \\
M_{s 2}=13,05 \mathrm{kN} \cdot 0,588 \mathrm{~m}+6,58 \mathrm{kN} \cdot 0,588 \mathrm{~m}=11,54 \mathrm{kNm}
\end{gathered}
$$

The transverse bending moment of the 'control' column will have the same absolute value but with a negative sign due to the previously adopted coordinate system for columns as bending beams.

The action of transverse moments on the lift columns is shown in Fig. 12. 


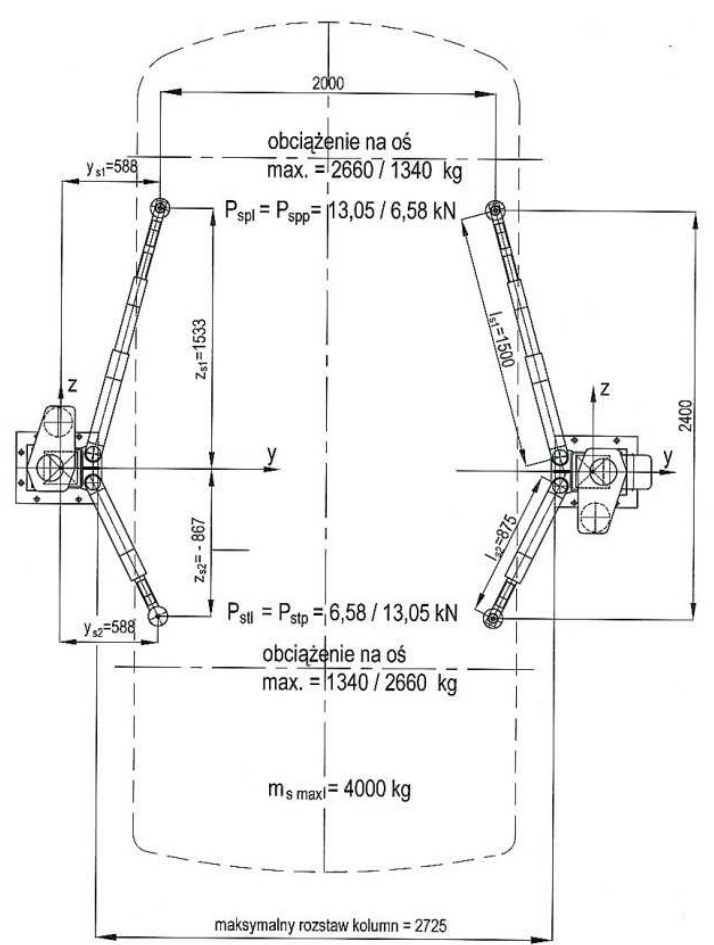

Fig. 11 Diagram of the adopted model of lifting the vehicle with astandard structure lift for calculating the column bending moment.

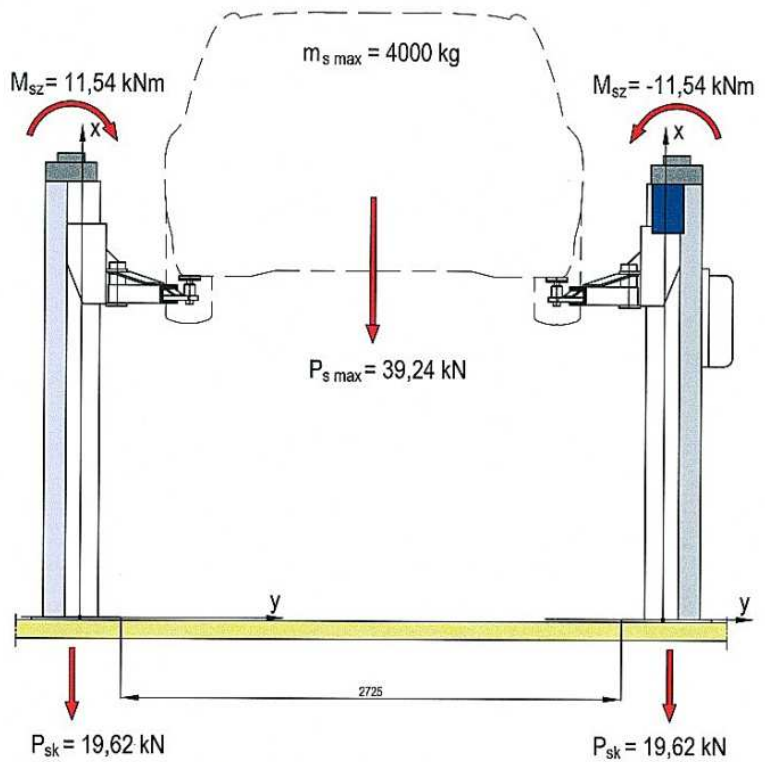

Fig. 12 Load on the columns with transverse bending moments for standard structure.

Calculation of the longitudinal bending moments for the 'control' column and the 'second' column:

- longitudinal moments for variation I of the load capacity distribution on the lifting arms:

$$
\begin{gathered}
M_{t z y 1}=P_{s p l} \cdot z_{s 1}=13,05 \mathrm{kN} \cdot 1,533 \mathrm{~m}=20,01 \mathrm{kNm} \\
M_{t s y 2}=P_{s t t} \cdot z_{s 2}=6,58 \mathrm{kN} \cdot(-0,867) \mathrm{m}=-5,70 \mathrm{kNm}
\end{gathered}
$$

- longitudinal moments for variation II of the load capacity distribution on the lifting arms:

$$
\begin{gathered}
M_{I l s y 1}=P_{s p l} \cdot z_{s 1}=6,58 \mathrm{kN} \cdot 1,533 \mathrm{~m}=10,09 \mathrm{kNm} \\
M_{I l s y 2}=P_{s t l} \cdot z_{s 2}=13,05 \mathrm{kN} \cdot(-0,867) \mathrm{m}=-11,31 \mathrm{kNm}
\end{gathered}
$$




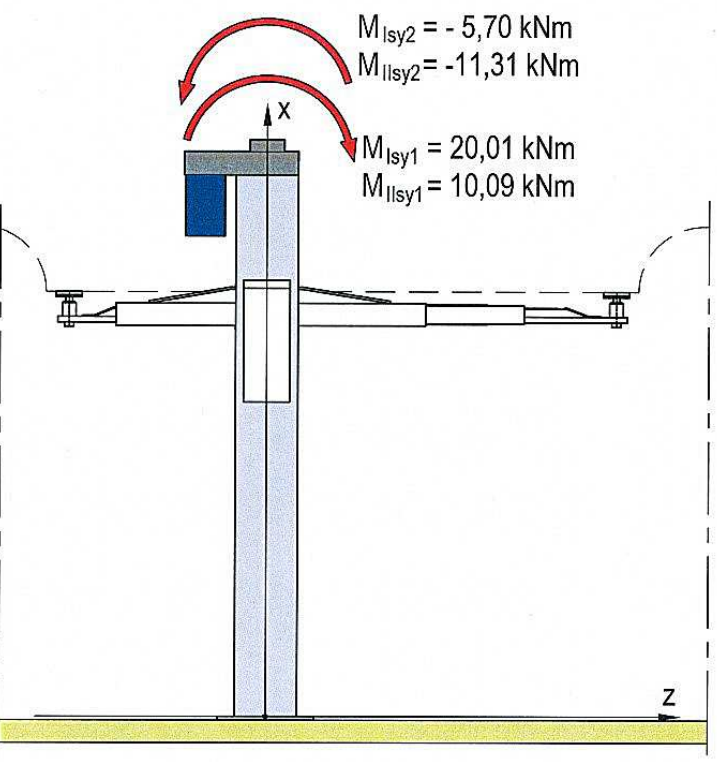

Fig. 13 Load on the columns with longitudinal bending moments for standard structure.

A resultant longitudinal bending moment for the column amounts to respectively:

- for variation I of the load capacity distribution on the lifting arms:

$M_{z g y}=M_{z g y_{1}}+M_{z g z_{2}}=20,01 \mathrm{kNm}-5,70 \mathrm{kNm}=14,31 \mathrm{kNm}$

- for variation II of the load capacity distribution on the lifting arms:

$$
M_{H s y}=M_{I s s y}+M_{I I s y 2}=10,09 \mathrm{kNm}-11,31 \mathrm{kNm}=-1,22 \mathrm{kNm}
$$

The following data was assumed for the structure after the modernisation when lifting the decompression chamber lid:

- maximum lifted weight $m_{\operatorname{mmax}}$ is equal to the weight of the lid together with the mounted test equipment and amounts to $m_{\operatorname{mmax}}=1,360 \mathrm{~kg}$,

- the distribution of the lifted weight is symmetrical with respect to the horizontal axes of the lid,

- the lid is lifted by 4 identical arms of the lifting unit and the points of supporting the lid with lugs are located symmetrically with respect to the lift columns,

- the load of the arm lugs of the lifting unit at the support points with the forces concentrated for the adopted symmetrical distribution of the lid weight is equal and amounts to $\mathrm{P}_{\mathrm{mj}}=3.34 \mathrm{kN}$.

On the basis of the above data, a model was adopted to determine the bending moments of the column in both bending planes - Fig. 14. In the lifting model, the following were adopted:

- column spacing: $\mathrm{B}_{\mathrm{m}}=1,614 \mathrm{~mm}$,

- arm length from the rotation axis on the trolley to the support point on the lug: $l_{\mathrm{m}}=549 \mathrm{~mm}$,

- $\quad$ he load of the arm lugs at the support points with the forces concentrated for the adopted symmetrical distribution of the lid weight: $\mathrm{P}_{\mathrm{mj}}=$ $3,34 \mathrm{kN}$.

Based on the diagram, the distances, along the ' $x$ ' and ' $y$ ' axes, of the points of applying concentrated forces from the rotation axis of the lifting unit arms were determined, assuming the axis of rotation as the place of attaching the rigid arm to the column.

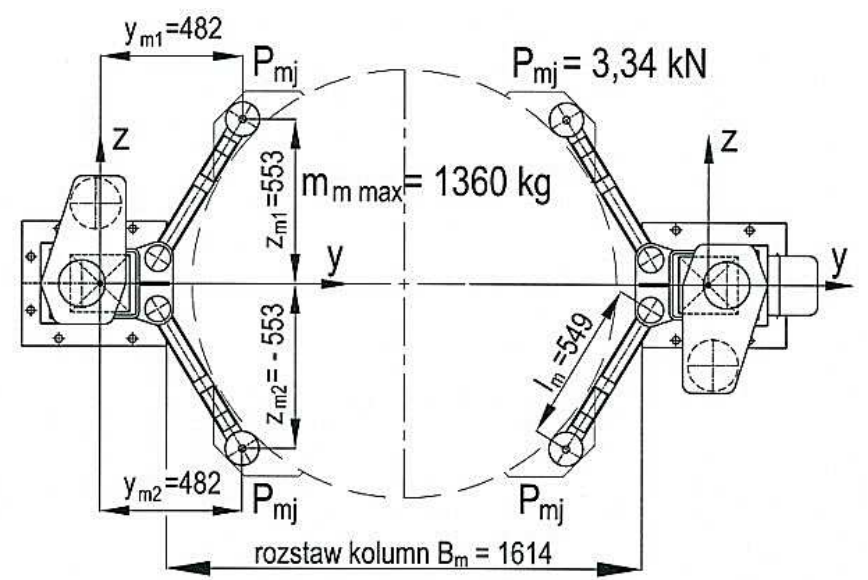

Fig. 14 A diagram of the adopted model of lifting the decompression chamber lid for calculating bending moments for the column of the lift after modernisation. 

respectively:

For the arms of the lifting units, the distances are

$$
\mathrm{y}_{\mathrm{m} 1}=\mathrm{y}_{\mathrm{m} 2}=\mathrm{y}_{\mathrm{m}}=482 \mathrm{~mm}, \mathrm{z}_{\mathrm{m} 1}=553 \mathrm{~mm}, \mathrm{z}_{\mathrm{m} 2}=-533 \mathrm{~mm}
$$

The calculation of the transverse bending moment of the 'second' column:
The transverse bending moment of the 'control' column will have the same absolute value but with a negative sign due to the previously adopted coordinate system for columns as bending beams.

The action of transverse moments on the lift columns is shown in Fig. 15.

$M_{m z}=M_{m z 1}+M_{m z 2}=P_{m j} \cdot y_{m 1}+P_{m,} \cdot y_{m 2}$
$M_{m z}=3,34 \mathrm{kN} \cdot 0,482 m+3,34 k N \cdot 0,482 m=3,22 k N m$

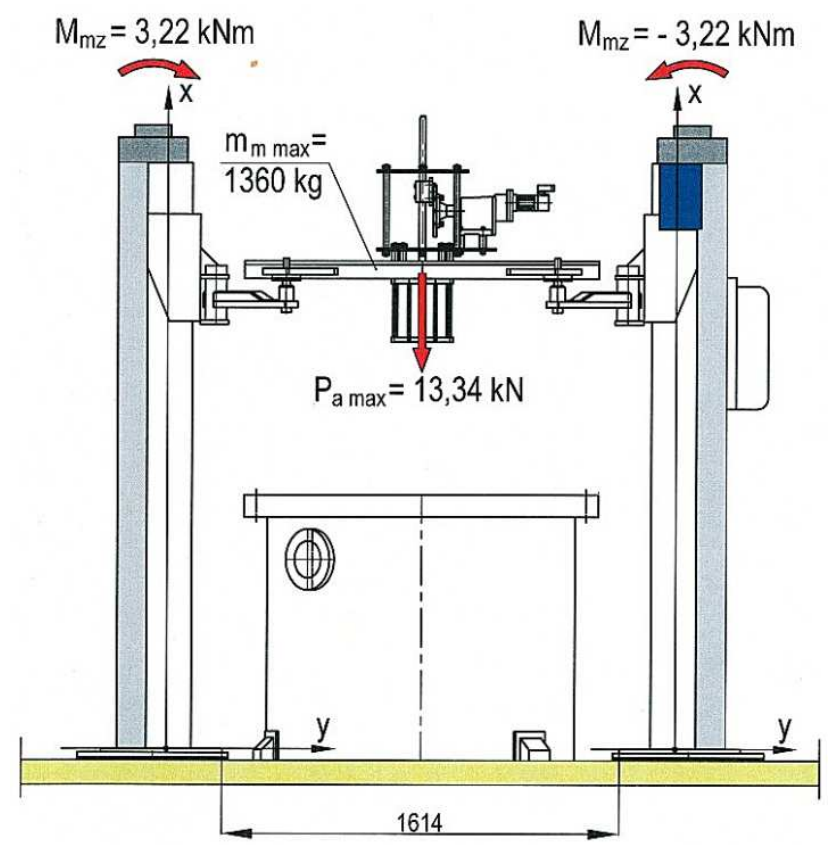

Fig. 15 Load on the columns with transverse bending moments for a lift after the modernisation.

Calculation of the longitudinal bending moments for the 'control' column and the 'second' column:

$$
\begin{gathered}
M_{m y 1}=P_{m j} \cdot z_{m 1}=3,34 k N \cdot 0,533 m=1,78 \mathrm{kNm} \\
M_{m y 2}=P_{m j} \cdot z_{m 2}=3,34 k N \cdot(-0,533)=-1,78 \mathrm{kNm}
\end{gathered}
$$

The action of longitudinal moments on the lift columns is shown in Fig. 15. 


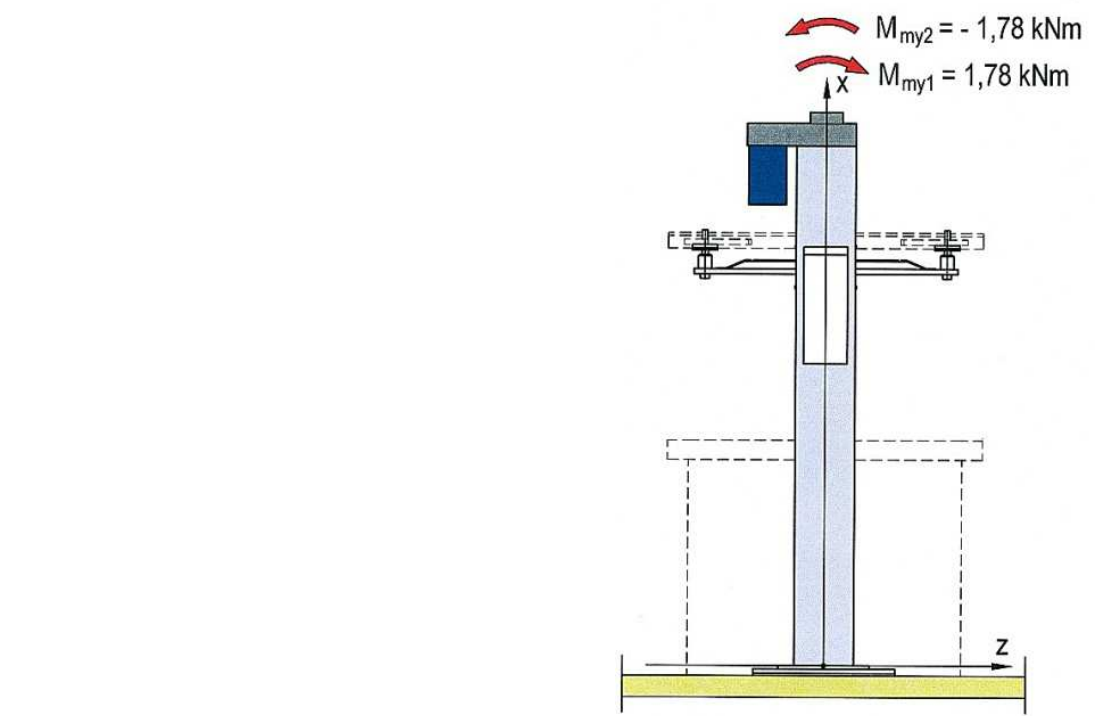

Fig. 16 Load on the columns with longitudinal bending moments for the construction after the modernisation. column is:

A resultant longitudinal bending moment for the

$$
M_{m y}=M_{m y 1}+M_{m y 2}=1,78 \mathrm{kNm}-1,78 \mathrm{kNm}=0 \mathrm{kNm}
$$

\section{BENDING MOMENTS OF THE LIFTING UNIT} ARM

Lifting objects using the lift arms causes the arms to bend. The value of the bending moment for the arm depends on the concentrated force acting on the arm's lug and the distance between the direction of this force and the arm's rotation axis in the fitting on the column trolley.

For the analysis of bending the lift arms, the maximum bending moments of the arms were determined for both compared structures.

The following data was used for lifting the vehicle in the standard structure (Instruction section II, pg. 7, fig. 7, fig. 8 and fig. 9):

- $\quad$ maximum weight lifted by $1 \mathrm{arm}$ msjmax $=1,330$ $\mathrm{kg}$, equal to half of the permissible load of one of the vehicle's axes,

- maximum distances between the direction of this force from the loading mentioned above and the arm's rotation axis in the fitting on the trolley ls1 $=1,500 \mathrm{~mm}$ for the arm at its maximum extension.

On the basis of the above data, a model was adopted to determine the maximum bending moment. In the lifting model, the following were adopted (Fig 16):

- maximum concentrated force for the adopted maximum weight lifted by 1 arm is: $P_{\text {Sjmax }}=13,05$ $\mathrm{kN}$,

- maximum distance of the direction in which the above-mentioned force acts from the point of fixing the lift's arm on the trolley $\mathrm{l}_{\mathrm{s} 1}=1,500 \mathrm{~mm}$.

Calculation of the maximum bending moment of the arm:

$$
M_{s s \max }=P_{s j \max } \cdot l_{s 1}=13,05 \mathrm{kN} \cdot 1,5 \mathrm{~m}=19,58 \mathrm{kNm}
$$

On the basis of the diagram, the bending moment was determined in the transverse section at the distance of $\mathrm{x}_{1}=1.07 \mathrm{~m}$ from where the arm is fixed on the column trolley. This is the section of the last element of the extendible arm (at the maximum extension) in the place of its 'restraint' in the middle part of the extendible arm. This moment is equal to $\mathrm{M}_{\mathrm{gs} 1}=5,61 \mathrm{kNm}$.

The following data was assumed for the structure after the modernisation when lifting the decompression chamber lid:

- $\quad$ the weight lifted by $1 \mathrm{arm} \mathrm{m}_{\mathrm{mj}}=340 \mathrm{~kg}$, equal to $1 / 4$ of the weight of the lid and the fitted test equipment,

- distances between the direction of this force from the loading mentioned above and the arm's rotation axis in the fitting on the trolley $\mathrm{l}_{\mathrm{m}}=549$ $\mathrm{mm}$ for the arm after the modernisation. 

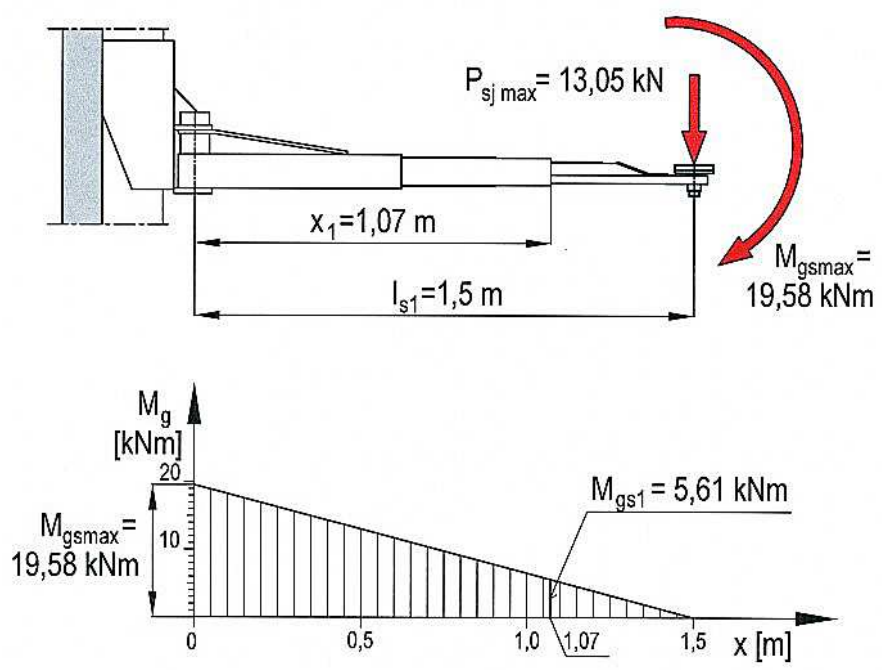

Fig. 17 The diagram of the adopted model of lifting a vehicle with a standard construction lift to calculate bending moments for the arm and a graph tracking the bending moments acting on the transverse section of the arm.

On the basis of the above data, a model was adopted to determine the maximum bending moment.

In the lifting model, the following were adopted -

Fig 18:

- maximum concentrated force for the adopted maximum weight lifted by one arm amounts to $\mathrm{P}_{\mathrm{mj}}=3,34 \mathrm{kN}$,

- the distance of the direction in which the abovementioned force acts from the point where the lift arm is fixed on the trolley $\mathrm{l}_{\mathrm{m}}=549 \mathrm{~mm}$.
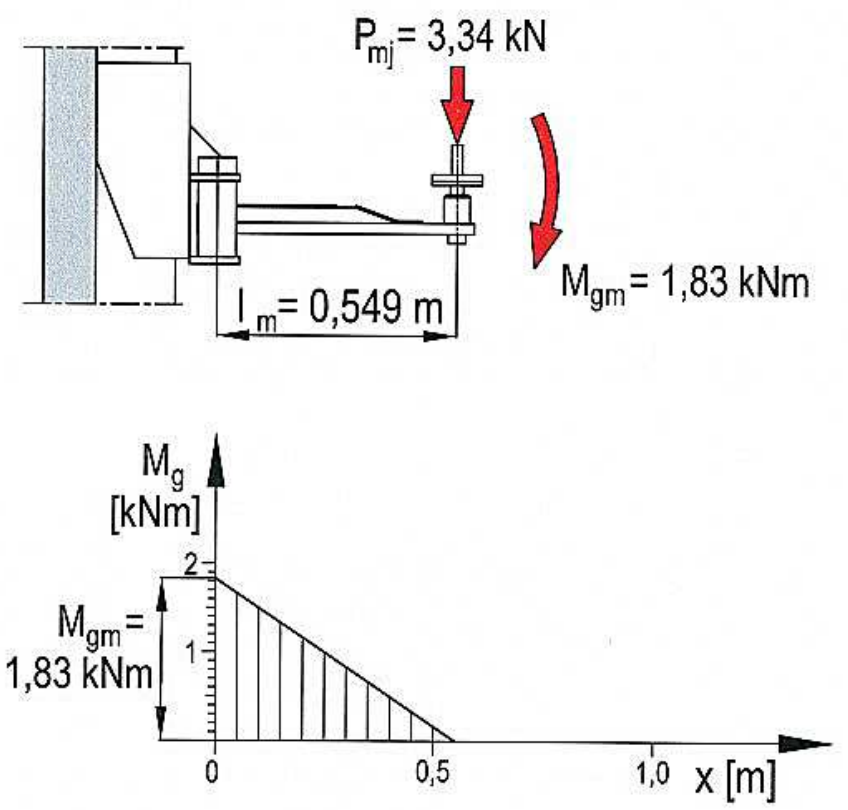

Fig. 18 The diagram of the adopted model for lifting the lid with the lift after the modernisation to calculate the bending moments for the arm and the diagram of bending moments acting on the transverse sections of the arm. 
the arm:

Calculation of the maximum bending moment of

$$
M_{g m}=P_{m j} \cdot l_{m}=3,34 k N \cdot 0,549 m=1,83 k N
$$

\section{COMPARATIVE ANALYSIS OF BOTH CAR LIFT STRUCTURAL SOLUTIONS WITH RESPECT TO THE LOADS OF THE LIFTED OBJECT ACTING ON THEIR ELEMENTS}

Table 2 shows a comparison of the operating loads (concentrated forces, pressure on the ground, moments of bending the elements of the construction) acting on the car lift in its standard version and after the modernisation.

Comparison of the operating loads of the lift in the analysed construction solutions

\begin{tabular}{|c|c|c|c|c|}
\hline \multirow[t]{2}{*}{ No. } & \multirow[t]{2}{*}{ The compared parameter } & \multicolumn{2}{|l|}{ The lift } & \multirow[t]{2}{*}{ Notes } \\
\hline & & $\begin{array}{l}\text { with standard } \\
\text { construction }\end{array}$ & $\begin{array}{l}\text { after the } \\
\text { modernisation }\end{array}$ & \\
\hline 1. & $\begin{array}{l}\text { Maximum force acting on the lift } \\
\text { from the weight of the object being } \\
\text { lifted }\end{array}$ & $\mathrm{P}_{\mathrm{smax}}=39,24 \mathrm{kN}$ & $P_{\max }=13,34 \mathrm{kN}$ & $\begin{array}{l}\mathbf{P}_{\operatorname{mmax}}<\mathbf{P}_{\text {smax }} \\
\text { approx. three times } \\
\text { lower }\end{array}$ \\
\hline 2. & $\begin{array}{l}\text { Maximum vertical force acting on } \\
\text { one lift column from the weight of the } \\
\text { object being lifted }\end{array}$ & $P_{\mathrm{sk}}=19,62 \mathrm{kN}$ & $P_{m k}=6,67 \mathrm{kN}$ & $\begin{array}{l}\mathbf{P}_{\mathbf{m k}}<\mathbf{P}_{\mathbf{s k}} \\
\text { approx. three times } \\
\text { lower }\end{array}$ \\
\hline 3. & $\begin{array}{l}\text { Pressure on the ground under } \\
\text { one column }\end{array}$ & $\mathrm{p}_{\mathrm{sk}}=0,112 \mathrm{~N} / \mathrm{mm}^{2}$ & $\mathrm{p}_{\mathrm{mk}}=0,145 \mathrm{~N} / \mathrm{mm}^{2}$ & $\begin{array}{l}\mathbf{p}_{\text {sk }} \approx \mathbf{p}_{\text {mk }} \\
\text { comparable values }\end{array}$ \\
\hline 4. & $\begin{array}{l}\text { Transverse bending moment for the } \\
\text { column }\end{array}$ & $\mathrm{M}_{\mathrm{sz}}=11,54 \mathrm{kNm}$ & $\mathrm{M}_{\mathrm{mz}}=3,22 \mathrm{kNm}$ & $\begin{array}{l}\mathbf{M}_{\mathbf{m z}}<\mathbf{M}_{\mathbf{s z}} \\
\text { approx. three times } \\
\text { lower }\end{array}$ \\
\hline \multirow[t]{4}{*}{5.} & $\begin{array}{l}\text { Longitudinal bending moment for } \\
\text { the column: }\end{array}$ & & & \\
\hline & - maximum positive: & $\begin{array}{l}\mathrm{M}_{\text {Isy } 1}=20,01 \mathrm{kNm} \\
\text { or } \\
M_{\text {IIsy1 }}=10,09 \mathrm{kNm}\end{array}$ & $\begin{array}{l}\text { constant value } \\
\mathrm{M}_{\mathrm{my} 1}=1,78 \mathrm{kNm}\end{array}$ & $\begin{array}{l}\mathbf{M}_{\text {my1 }}<\mathbf{M}_{\text {sy1min }} \\
\text { approx. six times lower }\end{array}$ \\
\hline & - maximum negative: & $\begin{array}{l}\mathrm{M}_{\text {Isy } 2}=-5,70 \mathrm{kNm} \\
\text { or } \\
M_{\text {IIy } 2}=-11,31 \mathrm{kNm}\end{array}$ & $\begin{array}{l}\text { constant value } \\
M_{\mathrm{my} 2}=-1,78 \mathrm{kNm}\end{array}$ & $\begin{array}{l}\left|\mathbf{M}_{\text {my2 }}\right|<\left|\mathbf{M}_{\text {sy2min }}\right| \\
\text { approx. three times } \\
\text { lower }\end{array}$ \\
\hline & $\begin{array}{l}\text { - resultant: } \\
\text { - for variation I } \\
\text { - for variation II }\end{array}$ & $\begin{array}{l}M_{\text {Isy }}=14,31 \mathrm{kNm} \\
M_{\text {IIsy }}=-1,22 \mathrm{kNm}\end{array}$ & $\begin{array}{l}\text { constant value } \\
\mathrm{M}_{\mathrm{my}}=0 \mathrm{kNm}\end{array}$ & $\begin{array}{l}\text { No resultant moment for } \\
\text { the solution after the } \\
\text { modernisation }\end{array}$ \\
\hline \multirow[t]{3}{*}{6.} & Lift arm bending moment & & & \\
\hline & - maximum & $\mathrm{M}_{\mathrm{gsmax}}=19,58 \mathrm{kNm}$ & $\mathrm{M}_{\mathrm{gm}}=1,83 \mathrm{kNm}$ & $\begin{array}{l}\mathbf{M}_{\mathbf{g m}}<\mathbf{M}_{\mathbf{g s m a x}} \\
\text { approx. ten } \\
\text { smaller }\end{array}$ \\
\hline & $\begin{array}{l}\text { - in the transverse section of the last } \\
\text { element of the extendible arm }\end{array}$ & $\mathrm{M}_{\mathrm{gs} 1}=5,61 \mathrm{kNm}$ & $\mathrm{M}_{\mathrm{gm}}=1,83 \mathrm{kNm}$ & $\begin{array}{l}\mathbf{M}_{\mathbf{g m}}<\mathbf{M}_{\mathbf{g s} \mathbf{1}} \\
\text { approx. three } \\
\text { lower }\end{array}$ \\
\hline
\end{tabular}


The strength analysis of the structural solutions of the car lift in its standard version and after the proposed changes made the following conclusions possible:

1. The basic load on the lift's structure after the modernisation with vertical forces resulting from the size of the lifted weight is approximately three times lower than that of the standard solution.

2. Bending moments for the column of the lift after the modernisation are many times lower than those in the standard solution.

3. There is no resulting longitudinal bending moment for the column of the car lift after the modernisation because the weight load on the lid is symmetrical and the lengths of the lifting arms are the same.

4. The bending moment in the lift arm after the modernisation in the transverse section at the point of restraint is approximately three times lower than the moment in the same section in the extendible arm for the standard solution.

5. The maximum bending moment for the lift arm after the modernisation at the point of restraint is approximately ten times lower than the moment at the point of restraint of the extendible arm for the standard solution. This means that the shear forces acting on the arm's pivot pin connected with the lift trolley are also approximately ten times lower than those in the standard solution after the proposed changes. The design of the pivot pin was not changed.

6. The resulting pressures on the ground on which the columns are fixed is comparable for both lift designs. This results from the selection of an appropriate surface area for the support lugs of the lift columns after modernisation in relation to the adopted vertical forces at work when the decompression chamber lid is being lifted.

\section{LIFT OPERATION CONTROL}

Lift operation during its standard use is controlled by means of a panel placed on one of the columns. The panel enables the following procedures to be performed:

- lifting or lowering the vehicle,

- $\quad$ aligning and levelling the lifting height for both column trolleys,

- voltage supply to the propulsion engines that rotate the lead screws, which in turn drive the lift trolleys,

- operation of the basic lift movement automation, such as limit switches and digital levelling synchronisation.

Fig. 19 shows the control panel that is mounted on one of the columns during its standard use.
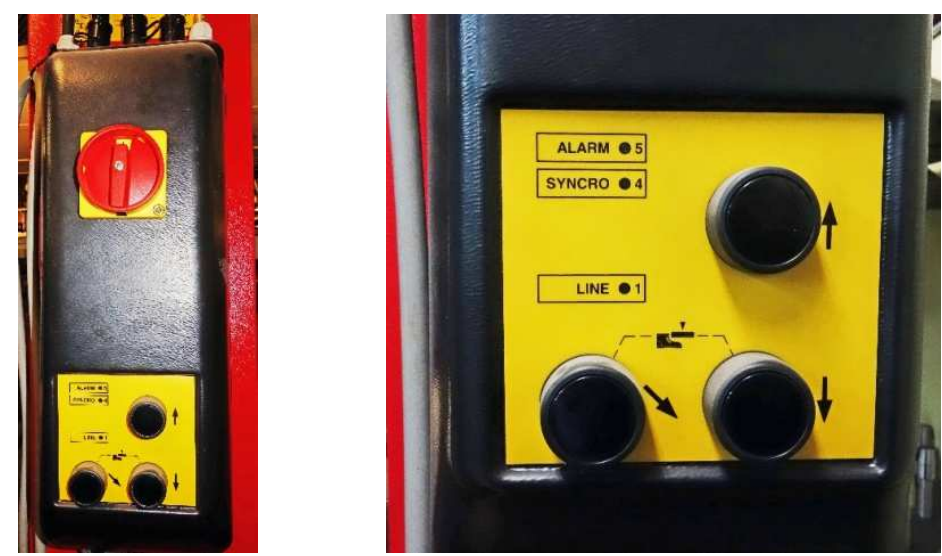

Fig. 19 Standard control panel that operates the lift.

A main switch that supplies power to the lift is mounted on the control panel. In its lower part there are three buttons and three indicator LEDs for the following purpose (Instruction, pg. 11):

- button: lifting up,

- button: lowering down,

- button: lowering down in the final phase with the warning signal activated,

- $\quad$ synchronisation control LEDs: Line 1, Syncro 4, Alarm 5.

The lift is operated at the same speed in both directions. Uneven lifting of objects between columns is due to uneven operation of the electric motors. This results in differences in the height of the lifting trolleys. In such a case, the vehicle tilts to one side. The re-levelling procedure is to be ensured by a digital synchronisation built into the control panel. If the level difference exceeds $50 \mathrm{~mm}$, the lift stops. The occurrence of such a situation means that the device is characterised by a low degree of precision. From the point of view of standard use of the lift, this feature does not significantly affect work at the garage. In the process of the planned modernisation of the lift, the precision of lifting the top lid of the decompression chamber is very important. This is due to the fact that the top mobile lid with a stationary flange welded into the body of the decompression chamber was sealed with 20 -rings made of silicone (oxygen-resistant rubber). In this solution, the tightness of the tank is achieved between the cylindrical inner surface of the tank flange and the side surface of the movable cover with gaskets placed in the grooves of the lid. 
Figure 20 shows the design solution for sealing the movable top lid in relation to the decompression chamber body.

With regard to the correctness of sealing, a structural clearance of tenths of a millimetre between the two parts is required. This state clearly indicated that the positioning of the lid in the flange requires relatively high precision. Coupling of these parts must be axial and the lid and the flange must be aligned to prevent any 'jamming' of the lid in the flange.
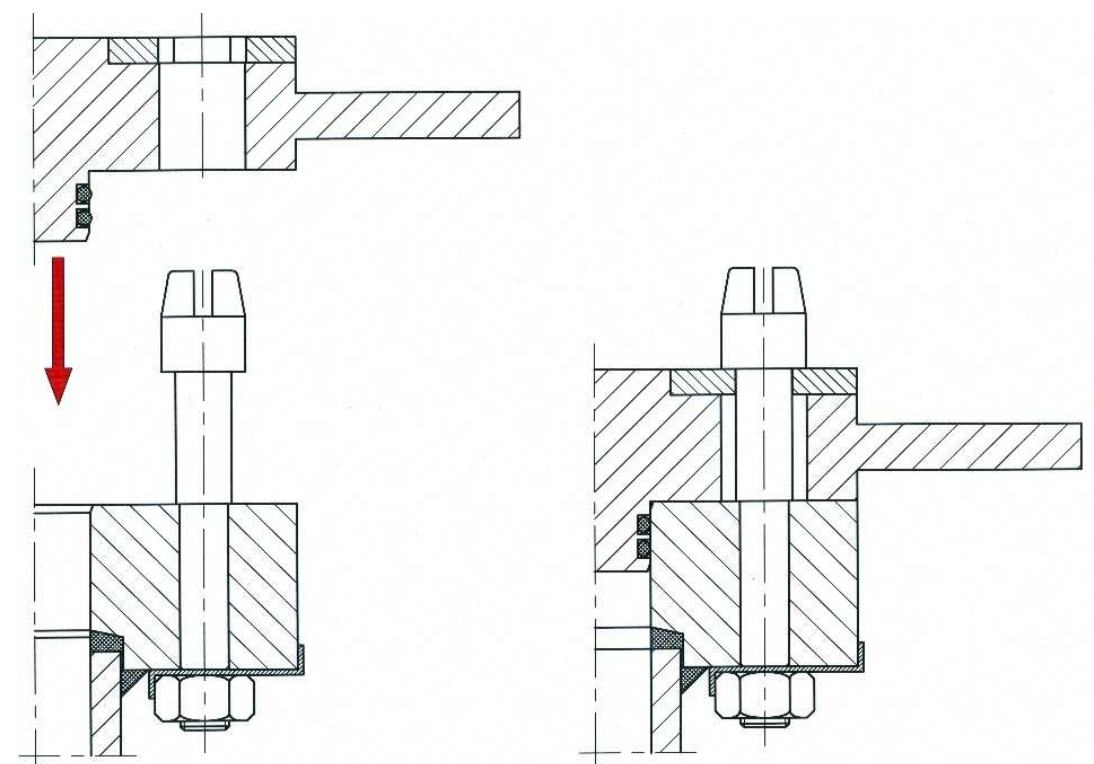

Fig. 20 Design solution for sealing the movable top lid in relation to the decompression chamber body.

Taking into account the existing conditions, it was concluded that the modernisation of the lift, in terms of carrying out the process of lifting and lowering the lid, should ensure, inter alia:

- $\quad$ precise control of variable speeds of the lifting trolleys,

- precise levelling of the lid in relation to the decompression chamber (tank) in such a way that its side sealing part is evenly inserted into the flange in the stationary pressure tank.

To solve this problem, it has been assumed that:

- $\quad$ precise adjustment of the lifting and lowering speed at different heights should be done by means of voltage inverters connected to electric motors, mounted on the elevator columns,

- horizontal adjustment of the decompression chamber lid in relation to the stationary flange should be done in real time by means of a precise digital level,

- the whole process of raising and lowering the lid after modernisation should be controlled by a computer using software specially developed for this purpose.

The analysis of the electric lift diagram (Instruction, pg. 17) has shown that it is possible to make a parallel connection to the existing installation in the lift with new actuators controlled by computer software. This means that the modernisation works would not result in any major changes to the existing electrical installation. It would be possible to control the operation of the device either with the original standard panel or with a digital system.

In order to further secure the operation of the lift, it was considered appropriate to equip the lift with two pairs of additional limit switches located on one of the columns between the switches originally installed. Their task would be to disconnect the power supply if the required range of operation was exceeded during lifting and lowering (Fig. 1) or if one of the switch pairs was damaged.

Fig. 21 shows a functional diagram of the electrical installation of the lift in which the proposed additional elements are marked in yellow.

Fig. 22 shows the proposed limit switch system on one of the lift columns. 


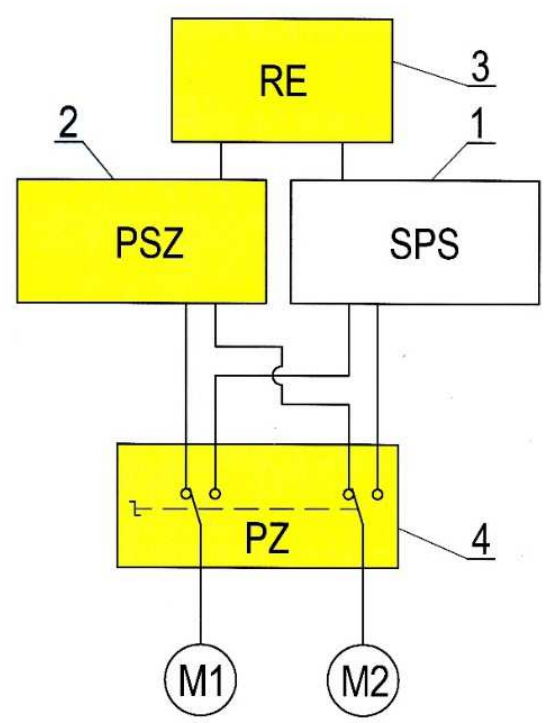

1 - SPS - Standard control panel for a two-column 254 S/4 lift

2 - PSZ - Control panel for a modernised lift

3 - RE - Electric switchgear with safeguards

4 - PZ - Power switch for the column motors of the lift

M1 - Electric motor of the left column

M2 - Electric motor of the right column

Fig. 21 Proposed functional diagram for the electrical installation of the lift

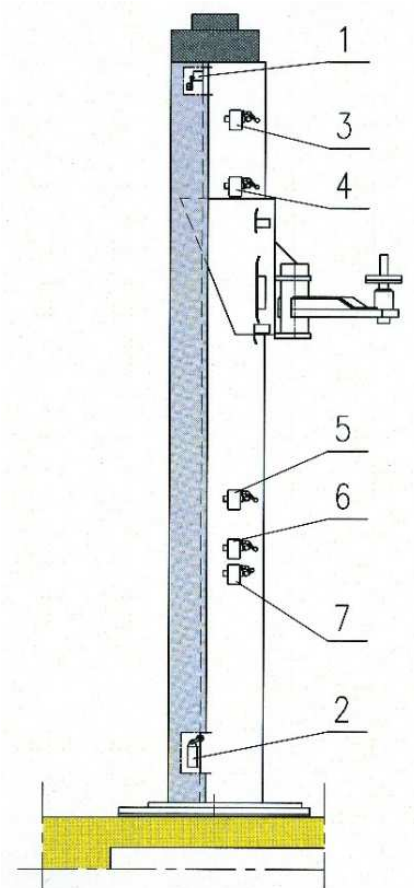

Fig. 22 Proposed arrangement of limit switches on one of the lift columns 1,2 - limit switches in the standard design of the lift, $3 \div 7$ - additional limit switches for lifting the lid.

Fig. 23 shows the proposed software interface for operating the lift using computer software designed by Arnold Dziambor, M.Sc. Eng, an employee of the Department of Underwater Works Technology at the Polish Naval Academy. 


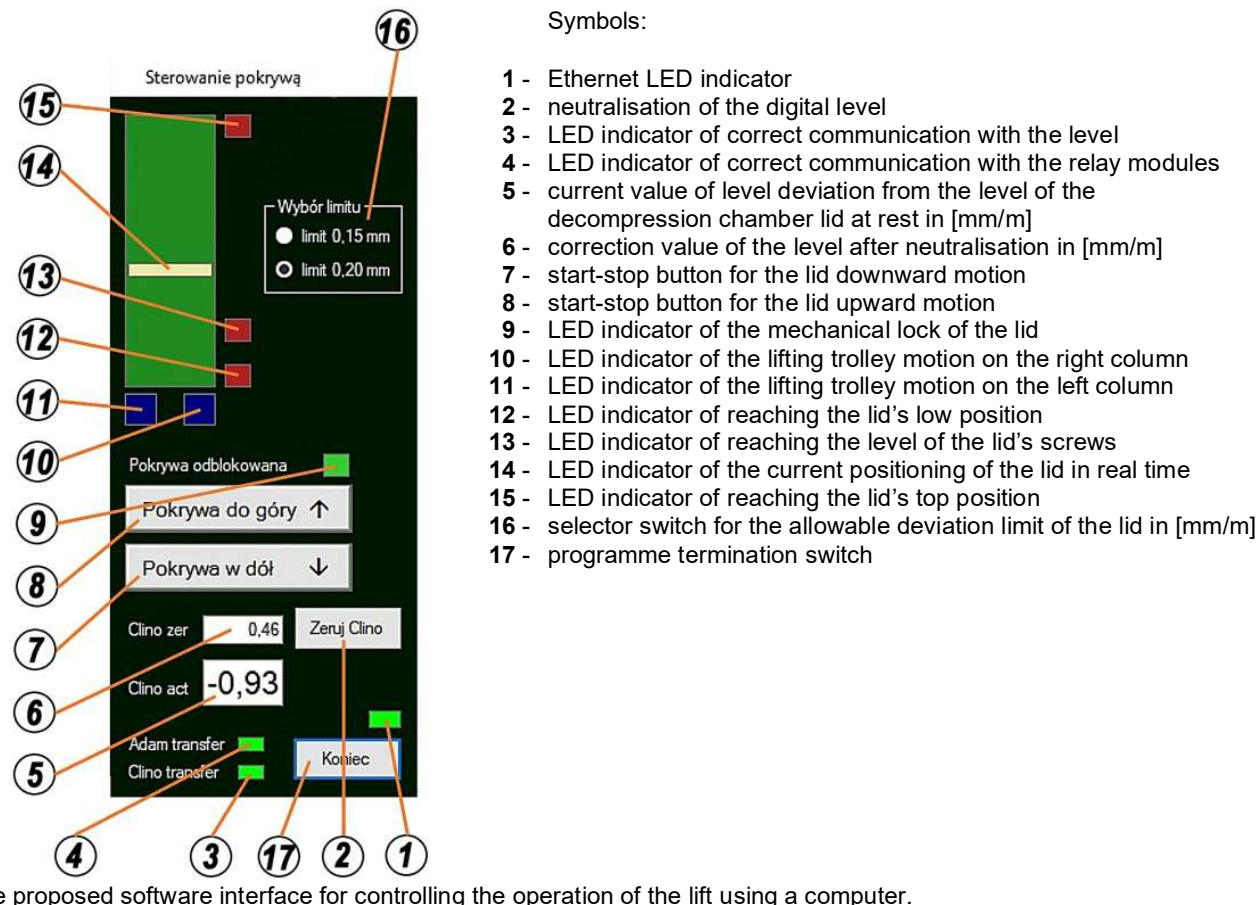

Fig. 23 The proposed software interface for controlling the operation of the lift using a computer.

\section{Conclusions}

On the basis of the conducted basic strength calculations and proposals for necessary changes in the lift's structure it can be stated that:

- the proposed structural changes which should be implemented in the modernisation process will in no case detract from the structural strength of the device. In the authors' opinion, this is synonymous with maintaining the previous utility values of the lift. It results from the fact that there is a significant reduction of the lifted weight, a reduction in the spacing of the columns and a shortening of the lifting arms resulting in a three-fold reduction in the loads on the machine's components;

- the exchanging of the lifted object, from a car to that of a lid of a pressure tank, does not change the basic function of the device, which is the vertical lifting/lowering of a specific weight within an acceptable, standard height and in a spatial system similar to the standard use;

- the positioning of the lifting columns on additional supports, which should be installed in a trench and properly fixed to the ground, is similar in strength to the conditions described in the instructions for use of the device. The supports align the column bases with the surface of the room;

- a structural change of the lugs mounted on the lifting arms, consisting in the axial addition of a locking pin, should prevent the lifted tank lid from slipping. In combination with the mechanisms that stop the rapid drop of lift trolleys originally installed in both columns [4], this set increases the safety of lift usage;

- the introduction of a computer control system for the process of lifting/lowering should significantly increase the precision of closing/opening the lid of the pressure tank. It should be noted that remote control of lifting the lid increases the operational safety of the device. The control panel can be placed at a greater distance from the lift and the associated danger zone.

\section{REFERENCES}

WERTHER International "Electromechanical, two-column lift 254 S/4" Manual v. 09.09 Werther International POLSKA;

254 S/4 car lift advertisement - www.wertherint.com (13.07.2019);

Office of Technical Inspection - https://www.udt.gov.pl/naprawy-i-modernicazje (13.07.2019);

Ph.D., Eng. M. Jankowski "Zabezpieczenia w podnośnikach samochodowych" [Safeguards in Car Lifts]

www.werther.pl/images/pisza/zabezpieczenia_w_podn_sam.pdf.

dr inż. Zbigniew Talaśka

Akademia Marynarki Wojennej im. Bohaterów Westerplatte

81-103 Gdynia 3 ul. Śmidowicza 69

Zakład Technologii Prac Podwodnych

tel. +586262746 , fax. +586253882

e-mail: zbigniew_talaska@wp.pl 